\title{
The Potential of Hot Springs in the Western Thailand for Health Tourism and Sustainability
}

\author{
Nipon Chuamuangphan \\ Nathon Pathom Rajabhat University, Nakhon Pathom, Thailand
}

\begin{abstract}
This research aims to examine the potential of hot spring sites in the Western Thailand for the purpose of sustainable tourism. The research applied qualitative methods and the participation of communities was included in the study's approach. The fieldwork consisted of the development of in-depth interviews, focus groups, field survey, and participation observation. Participants were stakeholders in tourism development. The data collected from interviews were analysed, interpreted, and reported with content and descriptive analysis. It was found that the hot spring destinations had their outstanding resources, based on their natural surrounded. The resources were used for tourism purpose in terms of health tourism. The potential of the various hot spring areas was divided into four groups. The first group included hot spring location where tourism data had not been gathered. The second group encompassed hot spring where tourism data had been gathered. The third group was hot springs where some tourism details had been gathered, but the hot spring sites were faced with some problems. The last group included well-developed hot spring locations where tourism data had been gathered before. All locations could be promoted for health tourism, and educational tourism could be added for tourist and the local community. Such development would need to be controlled by the community committees formed by representatives of all stakeholders directly and indirectly related to tourism development. Tourism development generated by community committees can result in sustainable development of hot spring destinations.
\end{abstract}

Keywords: tourism potential, hot spring, health tourism, sustainable tourism

\section{Introduction}

Tourism industry brings both income and more jobs to many countries, such as Thailand. The Thai government uses tourism as one tool to tackle the country's economic problems, creating jobs for people as well as increasing income for the country. Tourism has been strongly emphasized as a potential source of economic wealth for all geographical areas, particularly after the Asian economic crisis in 1997, and especially with the recognition that tourism can earn foreign currency more quickly than other sectors. Furthermore, tourism has been recognised since the Fourth National Economic and Social Development Plan (NESDP), 1977-1981 (NESDB, 2008), as having substantial potential benefits (Chittangwattana, 2005), and currently it is a major export industry for national and regional economic development. The Thai government recognised tourism as a means of assisting in development processes and in earning hard currency. Tourism has subsequently surpassed rice as the leading earner of foreign exchange for the country and cornerstone of its

Nipon Chuamuangphan, lecturer, Tourism Department, Nathon Pathom Rajabhat University, Nakhon Pathom, Thailand.

Correspondence concerning this article should be addressed to Nipon Chuamuangphan, Tourism Department, Nathon Pathom Rajabhat University, Nakhon Pathom, Thailand. 
economy (Tourism Authority of Thailand, 1997). From 1997, the decline in economic growth and in traditional exports in primary production and manufacturing resulted in growing indebtedness and a serious balance of payments deficit. Yet tourism receipts have risen from USD 37,740.00 million in 2013 to USD 46,042.00 million in 2014 (World Bank, 2015).

Tourism is regarded as a double-edged sword. On the one hand, tourism contributes to economic growth and can raise the income of individuals and nations. On the other hand, it produces many adverse impacts on host societies and their environments (Ounwichit \& Kaewkha, 2003; Buckley, 2004; Price \& Smith, 1996; Tribe, Font, Griffiths, Vickery, \& Yale, 2000). Due to the negative impacts of tourism on society and the environment in the country, the Thai tourism industry nowadays places emphasis on the concept of sustainable development. The Tourism Authority of Thailand recognises that it is essential to ensure that the regular visits of tourists are maintained and that tourism resources retain their integrity in order to maintain attractiveness (TAT, 2012a). Consequently, sustainable tourism is seen as a possible solution to the deterioration of the resources and it is used as a contributor to the conservation of the environment, society, and culture of the destination areas. In practice "sustainable tourism" is used as an umbrella term in Thailand for nature tourism, cultural tourism, and historical tourism, including health and hot spring tourism.

There are variety of patterns of tourism, it depends on tourism resources, activities in the area and the way of tourism be managed or designed to be. Some examples of tourism pattern are: natural tourism, cultural tourism, agrotourism, adventure tourism, trekking, and hot spring tourism. This study mainly focused on hot spring tourism as it is an alternative tourism for visitors who love travelling with concerning to their health in natural environment (TDRI, 1997). It meant that the sites of the research were natural hot spring emerged which provides some tourism activities and also tourism patterns in the areas. Moreover, the study viewed tourism environment all around the sites of study.

The Western Thailand, covered with seven provinces (Tak, Kampaeng Petch, Suphan Buri, Kanchana Buri, Ratcha Buri, Petcha Buri, and Prajueb Kiri Khan), has 18 hot spring sites. These hot springs sites have been used for both tourism and their daily living purposes. Some tourism sites have been developed and ready for tourism services, but had no plan for tourism development. These areas were left with some rubbishes and waste, including sewage form bathing and pools. And many of other sites had not yet prepared to be tourism destination as they were far away from the tourism accessing and the local people had no idea about tourism management (Kangnoi, 2009). Therefore, it is important to manage tourism as a right track of health tourism in these sites and to help the local community to find out their alternative ways to sustainable tourism.

Sharpley (2002) noted that although tourism is an important potential vehicle for economic development, sustainable tourism development also focuses on societal changes and natural resource conservation as well as on economic impacts. Sustainable tourism development is also often seen as requiring local community participation and involvement. In this study, sustainable development through tourism is evaluated in relation to the planning and management of health tourism (a concept that may be seen as part of sustainable development) [Tourism Authority of Thailand (TAT), 2001]. Actors' views are presented on the perceived appropriate patterns of social relations and the associated resulting patterns of resource use. As part of the focus on "insiders" or community actors, the study additionally considers community acceptance of the ways of making a living or "livelihoods" from natural resources, and the types and levels of participation and involvement in the development process. Consideration is also given to the extent to which planning and 
management for tourism development and health tourism, in particular-in both local and relevant national guidelines—reflect all actors' views about these issues.

\section{Study Aims}

1. To view all general information about all hot springs sites in the Western Thailand.

2. To evaluate tourism potential of all hot spring sites for health tourism to reach the health tourism standard in Thailand.

3. To find out patterns of health tourism and social relation and development.

\section{Related Works}

\section{Potential of Tourism}

Tourism Authority of Thailand (TAT) (1995) mentioned about potential of tourism that there must be something to be considered for tourism's potential. They are: 1) tourism attraction; 2) related activities to the tourism sites; 3) infrastructure; and 4) superstructure. They also claim that the potential and prompt of tourism in different areas are dominance from others. This depends on their resources, their beauty and aesthetic. Importantly, the variation of tourism sites had some outstanding resources which led their tourism to be in that pattern. Likewise, Sukhothai Thammathirath Open University (2002) and Tourism Authority of Thailand (TAT) (2012b) view about tourism's potential in Thailand that there are something to be thought about: 1) tourism physical; 2) quality of environment; 3) economic and social; 4) value of culture and arts; 5) value of education; and 6) efficiency of management. Thus, this study focuses on the potential of tourism in accordance with five factors following both the two authors. They are: 1) quality of tourism; 2) safety; 3) infrastructure; 4) management; and 5) value of tourism. Therefore, this study applied the hot spring tourism's potential in 1) quality of hot spring tourism; 2) safety at the sites; 3) infrastructure at hot spring sites; 4) management for health tourism; and 5) value of tourism.

\section{Health Tourism}

Tourism Authority of Thailand (TAT) (2012b); Boonchai and Thansarawiput (2003) explained about the meaning of health tourism that it is a pattern of travel for site visiting in both natural and cultural resources. While their traveling, the tourism will spend their some times for their health treatment and recovery (P. E. Cooper \& M. C. Cooper, 2009). Moreover, Sriwattananukulkij (2003) viewed that health tourism can be a pattern of tourism concerning about environmental conservation. They also mentioned that when the visitors take benefit from nature such as hot spring, they then would think about value of the hot spring. This can be a way for environmental conservation, hot water, and related activities in particular.

Therefore, hot spring tourism can be one of these three levels of health tourism. It can be the way treatment by hot water, as well as it could help to improve the visitor's body and make them relaxed while bathing in the hot water.

\section{Ideologies and Values of Sustainability}

Ideologies represent the underlying basis of our ideas and beliefs, a basis that gives them validity and credence (McCellan, 1986). The term is used in relation to beliefs that sustain existing relations, but it also applies to beliefs that challenge existing relationships. Ideologies often support the power of dominant economic and social groups but they also can be opposed to the prevalent bases of power and can be used to pursue changes in those power relations. They are related to how relationships of power are unavoidably 
interwoven into the production and representation of meanings that serve the interests of particular social groups (Mowforth \& Munt, 2003). In this context, sustainable development itself represents an ideological construct that it is largely derived from First World experiences and priorities and that has become mobilization as a global notion. It is now associated with global environmental issues, but it can be argued that the concept as it is often depicted tends to serve the interests of the First World. One reason why it may favor the First World is that it can hold back economic development and this can be thought to favor those nations that already have achieved reasonable levels of economic well-being. The First World nations were also able to secure their early economic growth without the environmental and social restraints that the sustainability concept entails. The power implicated through a universalistic First World view of sustainable development has led increasingly to the charge of eco-imperialism and eco-colonialism. This charge may be less appropriate if sustainable development is defined and negotiated within the local communities within the developing world itself in order to better reflect their situation, values, beliefs, and imperatives. This is a key premise of the present study.

Inevitably, there will be differing views or discourses related to the benefits of tourism for development. Some scholars adopt a narrow economic perspective and only consider the impacts for themselves or their immediate family, while others may consider the range of economic, environmental, social, and cultural benefits and relate those to the wider needs of the whole community. A more holistic approach to sustainability would require that the continuing social, cultural, and economic well-being of the whole community is an integral consideration (Richards \& Hall, 2002). Community-led sustainable development requires an understanding not just of the relationship between local communities and their environment, but also of the political, economic, and cultural tensions within communities. Such tensions within the community itself mean that there are often important differences in views and discourses about appropriate development among local residents (Richards \& Hall, 2002).

One key contested value or discourse related to local sustainable development concerns people's opinions about appropriate livelihoods or ways of making a living based on the actual or potential stock of local resources. The concept of sustainable livelihoods is used in academic work on local sustainable development. Rather less work has been done on people's own views about what comprises an appropriate livelihood. According to Bingen (2005, p. 1), the academic concept comprises three interrelated components:

(1) Some combination or portfolio of capabilities, assets (including physical, natural, and social resources or capital) and activities, (2) that enable people to deal with events and trends as well as develop various strategies to pursue desired livelihood outcomes, (3) while maintaining or enhancing their capabilities and asserts over the time. (Bingen, 2005, p. 1)

Bingen (2005, p. 1) explained that his "sustainable livelihood approach” (SLA) can help in programs for poverty eradication and for the enhancement of poor people's livelihoods. The approach can assist in evaluating local capabilities and assist in capacity and institution-building to promote these capabilities. The categories of institutions include, for example, familial institutions, communal (community) institutions, social institutions, collective institutions, and policy/governance institutions. These institutions tend to be seen at specific points in time, and they are important in supporting people's livelihoods throughout their lives. Such institutions are an important consideration in the present study.

Two potential objectives behind promoting participation and empowerment that are discussed in the literature are especially pertinent to the present study. First, such involvement might encourage residents to 
make decisions that protect the environment. Second, it might lead the locals to start small tourism businesses, which can secure greater economic benefits for the community and retain those benefits locally. In such ways, political empowerment can be accompanied by social and economic empowerment (Scheyvens, 2002).

In relation to tourism development, community participation tends to fall significantly short of empowerment. Indeed, often the purpose of tourism consultations is actually to persuade residents of the benefits of tourism rather than to empower them to make their own decisions (Sofield, 2003). Pearce, Moscardo, and Ross (1996) identified the concept of social representations as a means to understand how different community groups think about tourism, and they suggested that the results of such analysis can then be taken into account in the tourism planning process. But the frameworks proposed by researchers to understand the differing views about tourism within the community tend to be focused more on the process rather than on the outcome of community empowerment.

Grassroots empowerment is widely regarded as a fundamental of sustainability in tourism. As people become more empowered in decision-making processes, and as they become more involved in the entrepreneurial side of development, then their level of stewardship may increase: that is, stewardship of the environment, local culture, and the destination community in general (Timothy \& Boyd, 2003). This places the responsibility for upholding the principles of sustainability squarely in the hands of destination residents and other local stakeholders. The values, ideologies, and discourses of sustainable development inevitably relate to ideas about local benefits, and these need to be reflected in planning for sustainable tourism.

\section{Hot Spring}

Hot spring, also called thermal spring, is spring with water at temperatures substantially higher than the air temperature of the surrounding region. Most hot springs discharge groundwater that is heated by shallow intrusions of magma (molten rock) in volcanic areas. Some thermal springs, however, are not related to volcanic activity. In such cases, the water is heated by convective circulation: groundwater percolating downward reaches depths of a kilometre or more where the temperature of rocks is high because of the normal temperature gradient of the earth's crust-about $30^{\circ} \mathrm{C}\left(54^{\circ} \mathrm{F}\right)$ per kilometre in the first $10 \mathrm{~km}$ (six miles) (The Royal Institute, 2001). There are few more enjoyable experiences on a chilly winter night in the mountains of western part of Thailand than a dip in a natural hot spring. Thailand's hot springs are found in some of the country's most spectacular landscapes and provide visitors with the perfect balance of relaxation and natural beauty. The 18 hot spring sites in the west of Thailand have not yet been planned for tourism. A few of them have just been provided for tourism, the rest of that needed to be surveyed and more developed for tourism and health tourism purposes (DNP, 2015).

\section{Methods}

Qualitative research approaches are used in this study to assess and evaluate health tourism's potential and sustainable development. The intention of the study is to evaluate the interpretations that people have of themselves and others and also of their social situation, notably the views within the local communities in rural Thailand and from other related actors about hot spring and sustainable development in that context.

The approaches are also used in the study in order to capture the various actors' perspectives on hot spring tourism and sustainability. According to Silverman (2000), before conducting research it is important to set out the overall research approach clearly, as well as the related concepts, theories, methodologies, and methods. In 
the first place, the overall research approach provides a framework for how we look at reality (Silverman, 2005, p. 79). This research will draw strongly on ethnomethodology because it examines actors' social relations and their responses to the role of hot spring development within their local social context. Ethnomethodology, as an overall approach, encourages us to look at people's everyday ways of producing orderly social interaction. Using this constructivist strategy, this study will focus on human activities and experiences as based on the social relations, values, and discourses surrounding ecotourism and sustainability. A concept is an idea derived from the overall research approach and a theory is a set of concepts used to define and/or explain some phenomena. According to the theoretical positions identified by Jennings (2001), the present study adopts an ethnographic research approach because ethnography focuses on understanding questions of values, beliefs, and the psychology and culture of individuals and groups.

This research used several methods from qualitative research for its data collection. They are: document analysis, individual interviews (semi-structured interviews), participant observation, and observation. All the methods were structured under these contents: 1 ) the potential of hot spring tourism in accordance with five factors (quality of tourism, safety, infrastruture, management, and value of tourism) ; 2) tourism patterns; and 3) general information of hot spring tourism in the west of Thailand.

The data were analysed using content analysis, a technique that provides new insights and increases the researcher's understanding of particular phenomena. The approach to content analysis used here was thematic analysis, where the coding scheme was based on categories designed to capture the dominant themes present in the text (Franzosi, 2004, p. 550). Thematic analysis is a method for identifying, analyzing, and reporting themes with data. The process starts with the analyst looking for and noticing patterns of meaning and issues of potential interest in the data. The endpoint is the reporting of the content and the meaning of patterns or themes in the data, where "themes are abstract constructs the investigators identify before, during, and after analysis" (Ryan \& Bernard, 2000, p. 780).

\section{Results}

The study found that there were three main outcomes. They were general information to tourism of the hot springs in the west and tourism patterns at the hot spring sites. The result found that the potential of the various hot spring areas was divided into four groups.

(1) The first group (Figure 1) included hot spring location where tourism data had not been gathered. Their hot water temperature in between 40-51 Celsius, with poor quality for tourism as they are in the deep jungle and hardly accessing by road and no tourism facilities.

(2) The second group (Figure 2) encompassed hot spring where tourism data had been gathered with hot spring degree between 45-48 Celsius and the sites are preparing for hot spring tourism. But they face with valued tourism planning. These groups need some advices by health tourism planning consultation.

(3) The third group (Figure 3) were hot spring tourism sites where some tourism details had been gathered, but the hot spring sites were faced with some problems. These sites in the past were famous for health tourism. After tourism facilities construction and the effect from earthquakes, the hot water had gone away from the sites. These areas had no tourism as there are no natural hot water. Their temperatures are between 31-35 Celsius.

(4) The last (Figure 4) included well-developed hot spring locations where tourism data had been gathered before. They are very good sites for health tourism as their temperature are in between 39-72 Celsius. Tourism 
facilities are provided with some tourists safety process. The accessibilities are good in terms of transportation and road accessing and also local participation and management in tourism at the sites.

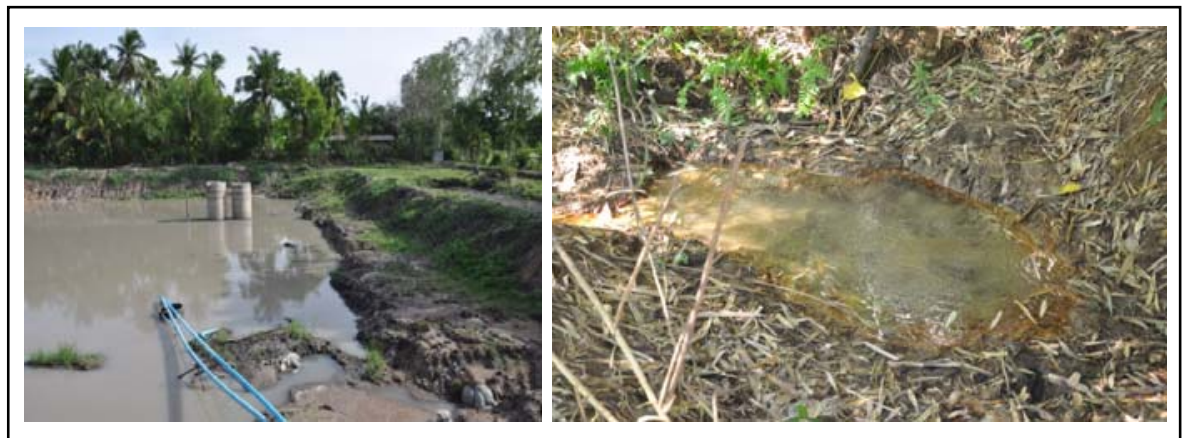

Figure 1. An example of poor quality hot spring site (the first group).

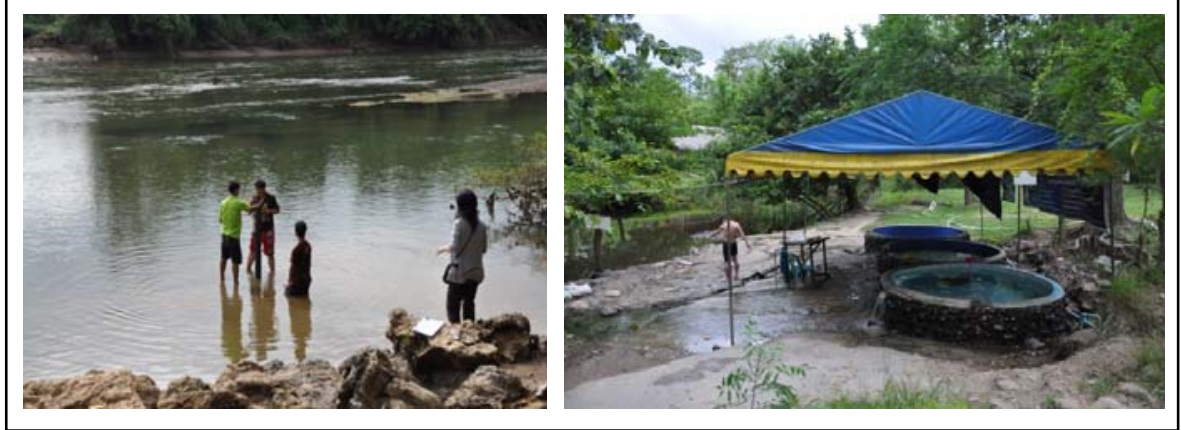

Figure 2. Examples of poor quality hot spring site, but preparing to development (the second group).

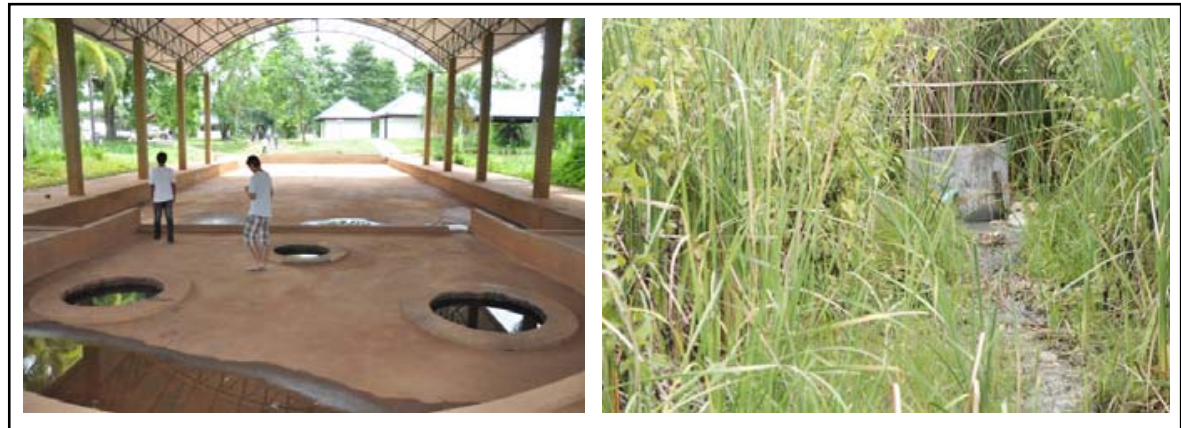

Figure 3. Examples of hot spring site faces with some problems (the third group).
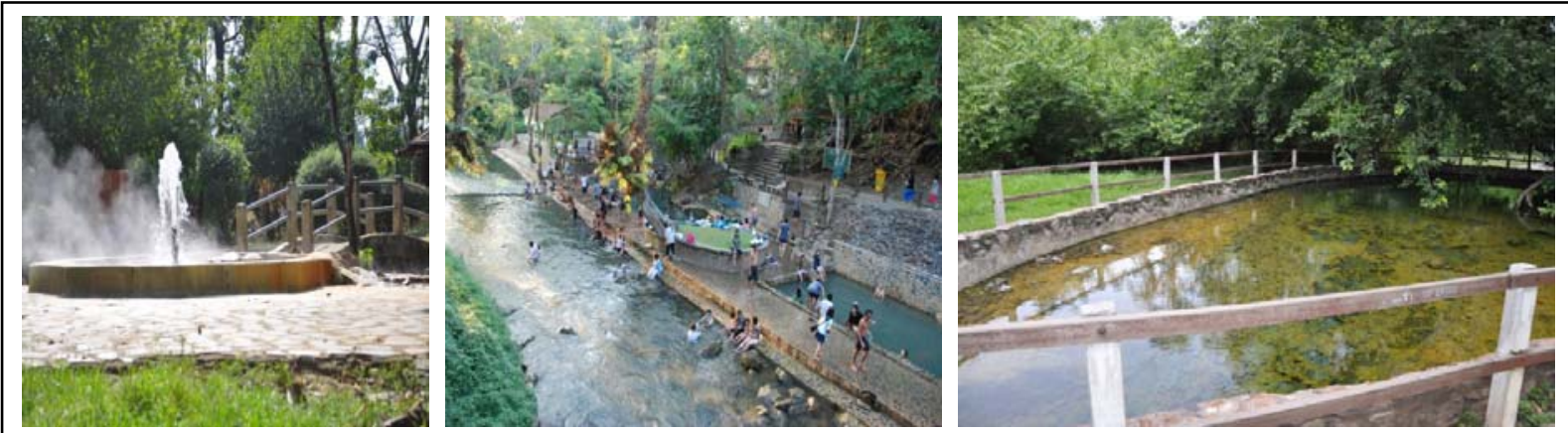

Figure 4. Examples of well-developed hot spring site (the last group). 
The patterns of tourism in the sites were found that most of the sites were prospered to be developed for health tourism. But some of the sites were lack of tourism management, some places were far away from community. Some others were faced with conflicts between local community and the administration, whereas one site faces with disappearing of hot water to other areas. Moreover, all of these tourism sites, if in right track of tourism management, they could be linked to surrounded tourism destinations, waterfalls, jungles, border, tribals, and some agricultural and historical areas. However, it needed good cooperation between organizations and local communities to tourism participation and empowerment by local people which was far away from tourism management in the areas.

Moreover, this study also had guidelines for landscape management in all tourism sites under local agreement. They are: 1) roads and access ways have to be reconsidered about the green; 2) buildings including shops and toilets visitor centre must be about local wisdom and traditional arts; 3) there must be relaxing zone provided some green facilities; 4) cleared signs; 5) keep clean; 6) traditional plants must be kept; 7) keep the hot spring pond as it was found; 8) green and eco lighting; 9) naturally walk way; 10) unique signs and name of the hot spring; and 11) easily accessing to car park and high way. All these designs and plans have to recognized about the local community participation, environmental conservation, and green zones.

\section{Conclusion and Future Works}

\section{Health Tourism and Sustainable Development}

The notion of health tourism is discussed and evaluated next. While many authors suggest varied definitions of health tourism and nature based tourism (all hot spring sites are in nature based), there are often common elements or principles. Cater (1997), Blamey (2001), and Orams (2001) indicated that the concept relates to nature based tourism that promotes environmental education and that is managed for sustainability. Similarly, Fennell (2008) suggested that:

Nature based tourism is a sustainable form of nature resource-based tourism that focuses primarily on experiencing and learning about nature, and which is ethically managed to be low-impact, non-consumptive, and locally oriented (in terms of control, benefits, profits, and scale). It typically occurs in natural areas, and should contribute to conservation or preservation of such areas. (Fennell, 2008)

That definition adds a locally oriented dimension. Lascurain (1996, p. 20) similarly defined nature based tourism as

Environmentally responsible travel and visitation to relatively undisturbed natural areas, in order to enjoy and appreciate nature (and any accompanying features—both past and present) that promotes conservation in hot springs, have low visitor impact, and provide for beneficial, active socio-economic involvement of local populations. (Lascurain, 1996, p. 20)

This definition also provides some emphasis on local benefits for residents.

\section{Social Relations and Sustainability}

A social relationship represents the existence of a probability of social interaction between two persons. In social relationships, the probability of interaction is increased if the two persons view themselves as members of a common collectivity. Social relations involve complex social roles among social actors (G. J. McCall, M. M. McCall, Deczin, Suttles, \& Kurth, 1970). In this study the social relations that are of interest relate to the planning and management of ecotourism and sustainability and to how people use and relate to their natural and 
cultural resources that can be useful for tourism development. Attention is directed to how actors use and feel about the use of resources for tourism development, and to their opinions about the concepts of appropriate and sustainable development in relation to resource use for tourism.

The study draws on a number of contested concepts. This applies to development, sustainability, and empowerment; and sustainable tourism development is widely considered to be as a subset of the contested broader concept of sustainable development. Community is also an ambiguous and much-debated term. This study has set out to understand the varied and differentiated community views about options for health tourism and sustainable development, taking as its point of departure the concept of community empowerment. The issues of community beliefs and discourses as well as empowerment go beyond the study of tourism impacts to consider processes that may be best understood using approaches based in sociological and political theory. It is argued that this expanded concept of empowerment constitutes a useful standpoint from which to consider community/tourism development relations (Sofield, 2003). By focusing on the social and political values, beliefs, and relations involved in health tourism and sustainable development, it is intended that the research will assist in a broader understanding of the socially constructed character of ecotourism management and sustainability. It seeks to situate the interpretation in the daily practices, beliefs, and relations in local communities in rural Thailand in order to develop an adaptive view of health tourism and sustainable development. In effect, it considers local community views on sustainable community development through tourism, but in the context on social interactions among national, regional, and local actors.

\section{Potential of Hot Springs}

The potential of hot spring areas was categorized to be four groups. The first group was hot spring tourism that data had not been gathered. Therefore, the development did not apply to them yet. According to an initial assessment, they were not potential enough to be attractions. The second group was hot spring that the tourism data had been gathered. They were developed for tourism purpose but face with environmental problems. The third was hot spring sites that some tourism details had been gathered. From an initial assessment, they were potential to be an attraction and they were being developed to be new attractions. The last was hot spring where tourism data had been gathered. They were potential to be attractions and the development had already been applied. However, proper development for tourism had to be adopted. The development of those hot spring locations should concern about the suitable pattern with tourism resources in area. Tourism resources have to be connected with all attractions in areas. Moreover, the participation of the community was a key to a success of development.

The future works related to this study should be focused on hot spring tourism sites management for health tourism and also about local community participation in tourism management for sustainability.

\section{References}

Bingen, J. (2005). Institutions and sustainable livelihoods. From the Forum on Operationalizaing Sustainable Livelihoods. In FAO Paper, 2005.

Blamey, R. K. (2001). Principles of ecotourism. In D. B. Weaver (Ed.), The encyclopedia of ecotourism (pp. 5-22). Wallingford: CABI. Boonchai, A., \& Thansarawiput, J. (2003). Health tourism. Thai Social and Economics, 40(4), 22-23.

Buckley, R. (2004). Environmental impacts of ecotourism. Cambridge: CABI.

Cater, E. (1997). Ecotourism in The Third World-Problems and prospects for sustainability. In L. France (Ed.), The earth scan reader in sustainable tourism (pp. 68-81). United Kingdom: Earthscan.

Chittangwattana, B. (2005). The development of sustanable tourism. Bangkok: Thammasart University Press. 
Cooper, P. E., \& Cooper, M. C. (2009). Health and wellness tourism: Spas and hot springs. New York: Channel View.

Department of National Park Thailand (DNP). (2015). Hot spring sites in Thailand. Retrieved on 12 July 2015 from http://www.ndp.go.th/

Fennell, D. (2008). Ecotourism (ed.). London: Routledge.

Franzosi, R. (2004). From world to numbers: Narrative data, and social science. Cambridge: Cambridge University Press.

Jennings, G. (2001). Tourism research. Milton: Wiley.

Kangnoi, J. (2009). Guidelines for hot spring tourism at Hindard, Kanchana Buri Province. Nakhon Pathom: Silapakhon University.

Lascurain, H. C. (1996). Tourism, ecotourism, and protected areas. Cambridge: IUCN.

McCall, G. J., McCall, M. M., Deczin, N. K., Suttles, G. D., \& Kurth, S. B. (1970). Social relations. Chicago: Aldine Publishing.

McCellan, D. (1986). Ideology. Milton Keynes: Open University Press.

Mowforth, M., \& Munt, I. (2003). Tourism and sustainability: Development and new tourism in The Third World. London: Routledge.

National Economic and Social Development Borad (NESDB). (2008). The 7th national economic and social development pland and creative economy (Year 1992-1996). Retrieved on 24 October 2014 from http://www.nesdb.go.th/Default.aspx?tabid=89

Orams, M. B. (2001). Types of ecotourism. In D. B. Weaver (Ed.), The encyclopaedia of ecotourism (pp. 23-36). Wallingford: CABI.

Ounwichit, C., \& Kaewkha, P. (2003). Karn Patta Marttratharn Khunnapap Karn Tongtiew Deonpa Khong Tambon Doi Hang, Amphur Muang, Chang wat Chiang Rai [Development of Trekking Tourism Standard in Tambon Doi Hang, Muang District, Chiang Rai Province], pp. 1-132. Bangkok: The Thailand Research Fund.

Pearce, P. L., Moscardo, G., \& Ross, G. F. (1996). Tourism community relationships. Oxford: Pergamon.

Price, M., \& Smith, V. (1996). People and tourism in fragile environment. Chichester: John Wiley \& Sons.

Richards, G., \& Hall, D. (2002). Tourism and sustainable community development. London: Routledge.

Ryan, G. W., \& Bernard, H. R. (2000). Data management and analysis methods. In N. K. Denzin and Y. S. Lincoln (Eds.), Handbook of qualitative research. London: Sage.

Scheyvens, R. (2002). Tourism for development: Empowering communities. Harlow: Prentice Hall.

Sharpley, R. (2002). Tourism and sustainable development: Exploring the theoretical divide. Journal of Sustainable Tourism, 8(1), $1-9$.

Silverman, D. (2000). Doing qualitative research: A practical hand book. London: Sage.

Silverman, D. (2005). Doing qualitative research: A practical hand book (ed.). London: Sage.

Sofield, T. H. B. (2003). Empowerment for sustainable tourism development. Kidlington: Elsevier Science.

Sriwattananukulkij, J. (2003). Tourism and the chage of tribal people. Chiang Mai: Social Research Institute, Chiang Mai University.

Sukhothai Thammathirat Open University. (2002). Thai tourism resources. Nonta Buri: Sukhothai Thammathirat Open University, $1-8$.

The Royal Institute. (2001). Hot spring. Bangkok: The Royal Institute.

Thailand Development Research Institute (TDRI). (1997). Thailand Tourism: Vision 2012, 12(2), 14-24.

Timothy, D. J., \& Boyd, S. W. (2003). Heritage tourism. Harlow: Prentice Hall.

Tribe, J., Font, X., Griffiths, N., Vickery, R., \& Yale, K. (2000). Environmental management for rural tourism and recreation. London: Cassell.

Tourism Authority of Thailand (TAT). (1995). The report of handout for tourism development. Bangkok: Core Planning and Development.

Tourism Authority of Thailand (TAT). (1997). Handout for tourism development in physical way. Bangkok:The Planning Section. Tourism Authority of Thailand (TAT). (2001). National ecotourism action plan. Bangkok: Conservation Division, Tourism.

Tourism Authority of Thailand (TAT). (2012a). Tourism statistic. Retrieved on 06 June 2015 from http:/www2.tat.or.th

Tourism Authority of Thailand (TAT). (2012b). Tourism standard for health tourism in Thailand. Bangkok: The Ministry of Tourism Thailand.

World Bank. (2015). World tourism revenues. Retrieved on 16 June 2015 from http://data.worldbank.org/ 